\title{
Short term outcome and predictors of survival among birth asphyxiated babies at a tertiary academic hospital in Enugu, South East, Nigeria
}

\author{
Nwachinemere D Uleanya ${ }^{1}$, Elias C Aniwada ${ }^{2}$, Uchenna Ekwochi ${ }^{1}$, Nwachinemere D Uleanya ${ }^{3}$
}

1. Department of Pediatrics Enugu State University Teaching Hospital, Enugu.

2. Department of Community Medicine, University of Nigeria Teaching Hospital, Ituku-Ozalla, Enugu.

3. P. O. Box 9225, Enugu, Enugu State. Nigeria.

\section{Emails:}

Nwachinemere D Uleanya: nulesa2001@yahoo.com, Elias C Aniwada: eaniwada@gmail.com, Uchenna Ekwochi: uekwochi@yahoo.co.uk, Nwachinemere D Uleanya: nulesa2001@yahoo.com

\begin{abstract}
Background: Birth asphyxia (BA) is a preventable cause of cerebral insults in newborns. It is associated with high morbidity and mortality. Of the 120 million babies born in third world countries annually, it is estimated that about 3.6 million will develop BA. Objectives: We aimed to determine the short term outcome and predictors of survival among birth asphyxiated babies using Apgar score.

Methods: This study was carried out in the Newborn Unit of Enugu State University Teaching Hospital. In-hospital deliveries (Inborn) and those from other centers (Out-born) with one minute Apgar score $\leq 6$ were included. Interviewer administered questionnaire was used to collect data from caregivers. Information sought included gestational age (GA), birth weight (BW), Apgar score, place of delivery and outcome. Data was analyzed using SPSS. Bivariate and multivariate logistic regressions were done.

Results: Of the 150 neonates, $61.3 \%$ survived. Majority of the dead were out-born. The difference was statistically significant ( $\mathrm{p}$ $<0.001$ ). The inborn were about 1.2 times (AOR $=1.22 ; 95 \%$ CI: 1.06-1.78) more likely to survive BA. Among low birth weights (LBWs), $73.9 \%$ died, $23.7 \%$ of normal weights and $14.3 \%$ of macrosomics died. The difference was statistically significant $(\mathrm{p}<$ 0.001). The normal weights were about 2 (AOR $=2.23,95 \% \mathrm{CI}: 1.76-6.25)$ and the macrosomics about 5 times more likely to survive BA than LBWs. Regarding GA, 78.8\%, $17.2 \%$ and $18.2 \%$ of the pre-terms, term and post-dates died respectively. The difference was statistically significant $(\mathrm{p}<0.001)$. The term babies were about 11 (AOR $=11.27 ; 95 \%$ CI: 4.02-31-56) and post -dates about 9 ( $\mathrm{AOR}=8.79 ; 95 \% \mathrm{CI}: 1.43-54.04)$ times more likely to survive $\mathrm{BA}$ than preterms. Other significant factors were degree of asphyxia $(\mathrm{p}=0.003)$, and parental education $(\mathrm{p}<0.001)$.

Conclusion: BW, GA, degree of asphyxia, place of delivery and parental education all predicts survival among birth asphyxiated newborns.
\end{abstract}

Keywords: Newborn, birth asphyxia, Hypoxic Ischemic Encephalopathy (HIE) outcomes, predictors of survival.

DOI: https://dx.doi.org/10.4314/ahs.v19i1.29

Cite as: Uleanya ND, Aniwada EC, Ekwochi U, ND U. Short term outcome and predictors of survival among birth asphyxiated babies at a tertiary academic hospital in Enugu, SoutbEast, Nigeria. Afri Health Sci. 2019;19(1). 1554-1562. https:// dx.doi.org/10.4314/abs.v19i1.29

\section{Corresponding author: \\ Nwachinemere D Uleanya, \\ Department of Pediatrics \\ Enugu State University Teaching Hospital, \\ Enugu.nulesa2001@yahoo.com}

\section{Introduction}

Birth asphyxia is a very common phenomenon in Africa and other third world countries, and is defined as the failure to initiate and sustain normal breathing at birth. ${ }^{1}$ This failure in the newborn, to initiate and breath normally ultimately leads to anoxia, increased carbon dioxide

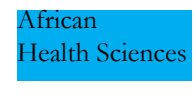

(C) 2019 Uleanya et al. Licensee African Health Sciences. This is an Open Access article distributed under the terms of the Creative commons Attribution License (https://creativecommons.org/licenses/BY/4.0), which permits unrestricted use, distribution, and reproduction in any medium, provided the original work is properly cited. 
accumulation and probably severe hypoxic ischemic organ damage. ${ }^{2,3}$ Birth asphyxia is the most significant preventable cause of cerebral insult in the newborn. ${ }^{4}$ It is a neonatal emergency and indeed a serious clinical problem globally. The encephalopathy that ensues is associated with a high risk of neurodevelopmental impairments among survivors such as cerebral palsy, functional disability, epilepsy and cognitive impairment later in childhood as full recovery may not occur and many children are left with life-long neurological impairment. ${ }^{5}$ This creates a great burden both psychologically, socially and economically for the family, the society and the patient.

Annually, approximately 4 million babies are born asphyxiated and it is estimated that $25 \%$ of the asphyxiated newborns die as a result of the asphyxia. ${ }^{1,5,6}$ Mortality rate associated with birth asphyxia annually is estimated to be about one million worldwide. ${ }^{1,25,6}$ Globally too, birth asphyxia accounts for $23 \%$ of neonatal deaths and about $10 \%$ of all deaths in children less than 5 years of age. ${ }^{5,7,8}$ Out of the 120 million babies born in third world countries each year, it is estimated that about 3.6 million (3\%) will develop birth asphyxia. ${ }^{9}$ Birth asphyxia is known to contribute significantly to the heavy neonatal, infant and under five mortality in Nigeria. ${ }^{10}$

Standard methods of assessment of asphyxia in a newborn will include umbilical artery $\mathrm{pH}, 1$-hour post-delivery blood gas measurement, Apgar scores, and neurological changes ranging from twitching to hypotonia and seizures., ${ }^{211,12}$ Although Apgar score alone is insensitive in predicting the neurodevelopmental outcome or individual neonatal mortality, it is fairly specific and provides an acceptable and convenient method for reporting the status of the newborn infant immediately after birth and the response to resuscitation if required. ${ }^{13,14} \mathrm{It}$ is still the most feasible and practical to perform, especially where there are limited resources. In spite of modern technology, while Apgar score is not the best tool for the identiication of newly born infants in need of cardiopulmonary resuscitation, it remains the best in evaluating the need for further resuscitative measures especially in the third world with scarce resources. Apgar scores of $\leq 6$ at 1, 5 and 10 minutes have been found to be indicators of an increased risk of mortality or chronic motor disability. ${ }^{2,15}$ In Nigeria, as in any other third world, birth asphyxia is crudely assessed using the Apgar score. In spite of improvements in the obstetric and neonatal care, the incidence of birth asphyxia is still very high as in other developing countries. The neonatal morbidity and mortality as a result of birth asphyxia is still comparatively high but what determines survival? To the best of our knowledge, there is no study in Africa that has assessed what factors determine survival among asphyxiated babies. This study therefore aims to determine the short term outcome and the predictors of survival among birth asphyxiated babies using the Apgar score, in a Special Care Baby Unit in Enugu, SouthEast Nigeria.

\section{Methods}

This was an analytical prospective study done from July 2015 to June 2016 in the Newborn Special Care Baby Unit (SCBU) of Enugu State University Teaching Hospital, Enugu. It is the only emergency newborn unit in Enugu municipality providing tertiary neonatal care for the state. It admits about 260 newborns in a year. Ethical clearance was obtained from the Enugu State University Teaching Hospital Health Research and Ethics Committee. Both written and oral informed consent was obtained from each parent(s)/caregiver and confidentiality maintained in the entire study. All newborns delivered within the hospital (Inborn) with Apgar score $\leq 6$ at one minute and those referred from other delivery centers (Outborn) with documented Apgar score $\leq 6$ on presentation or with no assigned Apgar score but with a history of poor or inability to cry at birth, with poor or dusky color, in respiratory distress and floppy were included. All babies in the study were studied from day of admission and followed up till discharge or death. Exclusion criteria included all newborns who did not present with the features mentioned above and those with such features older than 24 hours at presentation, those whose parent(s)/ caregiver did not consent as well as any newborn with congenital malformation, maternal narcotic drug use and abdominal distention.

Data was collected from the medical record and with a structured interviewer administered questionnaire administered to parent(s)/caregiver of each child. Some of the information sought included: gestational age (GA), sex, birth weight (BW), Apgar score, mode of delivery, place of delivery and duration of hospitalization. Our main 
outcome measures were mortality and discharge (survival). For the purposes of this study, moderate asphyxia was defined as Apgar score of 4-6 while 0-3 defined severe birth asphyxia.

All data were analyzed using Statistical Package for Social Sciences software version 20. Tables were constructed as appropriate. Associations between GA, BW, sex, mode of delivery, place of delivery and outcome were determined using Chi-square test. Binary logistic regression was done to ascertain predictors of outcome. $\mathrm{P}$ value at level of $\leq$ 0.05 was accepted as significant.

\section{Results}

During this period, a total of 150 neonates who met the inclusion criteria were admitted into the NBSCU with Apgar scores of $\leq 6$. Ninety $(60 \%)$ of these births were through vaginal delivery, 57 (38\%) were through cesarean sections while $3(2 \%)$ were assisted deliveries. Fifty-five $(36.7 \%)$ of these babies were delivered in the hospital (In-born) while 95 (63.3\%) were out-born. Seventy-one
$(47.3 \%)$ were males while the rest were females. Of the 150 asphyxiated babies, $52(34.7 \%)$ were pre-term (GA $\leq$ 36 weeks), 87 (58.0\%) were term (GA 37-40 weeks) while $11(7.3 \%)$ were post-date ( $>40$ weeks) with mean GA of $36.8 \pm 3.8$ weeks. There were 46 (30.66\%) LBW babies, weighing < 2500 g, $97(64.66 \%)$ normal weight babies who weighed $2500-4000 \mathrm{~g}$ and 7 (4.66\%) macrosomic babies weighing $>4000 \mathrm{~g}$. The mean BW of the babies was $2800 \mathrm{~g} \pm 850$ while their BW range was between $1000-5000$ g. Seventy-three (48.7\%) had severe asphyxia while $77(51.3 \%)$ suffered moderate birth asphyxia. Most $(51.3 \%)$ of the mothers of these babies had secondary school education, $37.3 \%$ had tertiary education while $11.3 \%$ had primary or no formal education. Also among the fathers of these babies, $51.3 \%$ had secondary education, $32 \%$ had tertiary education while $16.7 \%$ had primary or no formal education table I. The mean duration of hospitalization of these asphyxiated babies was $9.3 \pm 6.5$ days. While the survivors' mean duration of hospitalization was $10.7 \pm 4.2$ days, the non-survivors' mean duration of hospitalization was $7.1 \pm 2.6$ days. 
Table I: Clinico-demographic characteristics of asphyxiated newborns

\begin{tabular}{|c|c|c|}
\hline & $\begin{array}{l}\text { Frequency } \\
(n=150)\end{array}$ & $\begin{array}{l}\text { Percent } \\
(100 \%) \\
\end{array}$ \\
\hline \multicolumn{3}{|l|}{ Sex } \\
\hline Male & 71 & 47.3 \\
\hline Female & 79 & 52.7 \\
\hline \multicolumn{3}{|l|}{ Mode of delivery } \\
\hline Vaginal & 90 & 60 \\
\hline Cesarean section & 57 & 38 \\
\hline Assisted & 3 & 2 \\
\hline \multicolumn{3}{|l|}{ Gestational Age (weeks) } \\
\hline$\leq 36$ & 52 & 34.7 \\
\hline $37-40$ & 87 & 58.0 \\
\hline$>40$ & 11 & 7.3 \\
\hline \multicolumn{3}{|l|}{ Asphyxia } \\
\hline Moderate & 77 & 51.3 \\
\hline Severe & 73 & 48.7 \\
\hline \multicolumn{3}{|l|}{ Place of birth } \\
\hline Inborn & 55 & 36.7 \\
\hline Out born & 95 & 63.3 \\
\hline \multicolumn{3}{|l|}{ Birth Weight } \\
\hline$<2500 \mathrm{~g}$ & 46 & 30.7 \\
\hline $2500-4200 \mathrm{~g}$ & 97 & 64.7 \\
\hline$>4200 \mathrm{~g}$ & 7 & 4.6 \\
\hline Mean Birth weight & $2.80 \pm 0.85 \mathrm{~kg}$ & \\
\hline \multicolumn{3}{|l|}{ Mothers' Educational level } \\
\hline No formal/Primary education & 17 & 11.3 \\
\hline Secondary & 77 & 51.3 \\
\hline Tertiary & 56 & 37.3 \\
\hline \multicolumn{3}{|l|}{ Fathers' Educational level } \\
\hline No formal/Primary education & 25 & 16.7 \\
\hline Secondary & 77 & 51.3 \\
\hline Tertiary & 48 & 32.0 \\
\hline
\end{tabular}

Of the 150 asphyxiated babies, 58 (38.7\%) died while $92(61.3 \%)$ were discharged. Among the 58 that died, $8(14.5 \%)$ were inborn and $50(52.6 \%)$ were delivered outside the hospital. The difference was statistically significant $\left(\chi^{2}=21.31, \mathrm{p}<0.001\right)$. Eight of these babies died within the first 24 hours. All were out-born and suffered severe asphyxia. Among those babies with BW $<2500 \mathrm{~g}, 34(73.9 \%)$ died, while among those weighing 2500 - 4000g, 23 (23.7\%) died. The difference was also statistically significant $\left(\chi^{2}=34.76, \mathrm{p}<0.001\right)$. With regards to gestational age, among the pre-terms, $41(78.8 \%)$ died while $15(17.2 \%)$ of the term babies died (table II). 
There was also statistically significant difference between the groups $\left(\chi^{2}=54.18, p<0.001\right)$. Degree of asphyxia $(p=0.003)$, and educational level of parents $(p<0.001)$ were all significantly associated with survival. The factors namely sex and mode of delivery were not statistically associated with survival (table II).

On multivariate analysis, the normal weight babies were about 2 times (AOR $=2.23$; 95\% CI: 1.76-6.52), while the macrosomics were about 5 times $(\mathrm{AOR}=5.12$; 95\% CI: 2.42-61.83) significantly likely to survive asphyxia than the LBW babies who suffered asphyxia. Between the degrees of asphyxia, those babies who suffered moderate asphyxia were about 3 times (AOR $=3.26$; 95\% CI: 1.10-9.64) significantly more likely to survive than those who suffered severe asphyxia. With regards to place of delivery, the inborns were about 1.2 times $(\mathrm{AOR}=1.22$; 95\% CI: 1.06-1.78) more likely to survive birth asphyxia than those delivered outside the hospital. Regarding gestational age, the term babies who suffered asphyxia were about 11 times (AOR $=11.27$; 95\% CI: 4.02-31.56) and the post-dates about 9 times $(\mathrm{AOR}=8.79 ; 95 \% \mathrm{CI}: 1.43$ 54.04) more likely to be discharged than the preterms. Considering parental education, those asphyxiated babies whose mother had no formal or primary education had about $20 \%$ chances of survival while those whose mother had secondary education had about $80 \%$ chances of survival compared with those whose mother had tertiary education. Also, compared with fathers with tertiary education, those babies whose father had no formal or primary education had about $20 \%$ chance of survival (table II). 
Table II: Short term outcomes and predictors of survival

\begin{tabular}{|c|c|c|c|c|}
\hline & \multicolumn{2}{|c|}{ Short term outcome } & \multirow{2}{*}{$\begin{array}{l}\text { Bivariate } \\
\text { analysis } \\
\chi^{2} \\
\text { (p value) }\end{array}$} & \multirow{2}{*}{$\begin{array}{l}\text { Multivariate analysis } \\
\operatorname{AOR}(95 \% \mathrm{CI})\end{array}$} \\
\hline & $\begin{array}{l}\text { Died } \\
\text { Freq }(\%)\end{array}$ & $\begin{array}{l}\text { Survived/ } \\
\text { Discharged } \\
\text { Freq (\%) }\end{array}$ & & \\
\hline \multicolumn{5}{|l|}{$* \operatorname{Sex}$} \\
\hline Male & $25(35.2)$ & $46(64.8)$ & 0.679 & NA \\
\hline Female & $33(41.8)$ & $46(58.2)$ & $(0.410)$ & \\
\hline \multicolumn{5}{|l|}{ *Gestational Age (Weeks) } \\
\hline$\leq 36$ & $41(78.8)$ & $11(21.2)$ & 54.18 & \\
\hline $37-40$ & $15(17.2)$ & $72(82.8)$ & $(0.000)$ & $11.27(4.02-31.56)$ \\
\hline$>40$ & $2(18.2)$ & $9(81.8)$ & & $8.79(1.43-54.04)$ \\
\hline \multicolumn{5}{|l|}{ *Degree of Asphyxia } \\
\hline Moderate & $21(27.3)$ & $56(72.7)$ & 8.67 & \\
\hline Severe & $\begin{array}{l}37 \\
(50.7)\end{array}$ & $36(49.3)$ & $(0.003)$ & $3.26(1.10-9.64)$ \\
\hline \multicolumn{5}{|l|}{ *Mode of Delivery } \\
\hline Vaginal & $38(42.2)$ & $52(57.1)$ & & \\
\hline Cesarean Section & $\begin{array}{l}19 \\
(33.3)\end{array}$ & $38(66.7)$ & 1.99 & NA \\
\hline Assisted & $(33.3)^{1}$ & $2(66.7)$ & $(0.55)$ & \\
\hline \multicolumn{5}{|l|}{ *Birth Weight (g) } \\
\hline$<2500$ & $34(73.9)$ & $12(26.1)$ & 34.99 & \\
\hline $2500-4000$ & $23(23.1)$ & $74(76.9)$ & $(0.000)$ & $2.23(1.76-6.52)$ \\
\hline$>4000$ & $1(14.3)$ & $6(85.7)$ & & $5.12(2.42-61.83)$ \\
\hline \multicolumn{5}{|l|}{ *Place of Birth } \\
\hline Inborn & $8(14.5)$ & $47(85.5)$ & 21.31 & \\
\hline Outborn & $50(52.6)$ & $45(47.4)$ & $(0.000)$ & $1.22(1.06-1.78)$ \\
\hline \multicolumn{5}{|l|}{ *Maternal Educational level } \\
\hline No formal/Primary Education & $(41.2)^{7}$ & $10(58.8)$ & & \\
\hline Secondary Education & $40(51.9)$ & $37(48.1)$ & 14.32 & $0.19(0.04-0.91)$ \\
\hline Tertiary Education & $11(19.6)$ & $45(80.4)$ & $(0.001)$ & $0.8(0.01-0.58)$ \\
\hline \multicolumn{5}{|l|}{ *Paternal Educational level } \\
\hline No formal/Primary Education & $6(24.0)$ & $19(76.0)$ & 14.19 & \\
\hline Secondary Education & $41(53.2)$ & $36(46.8)$ & $(0.001)$ & $0.21(0.05-0.91)$ \\
\hline Tertiary Education & $11(22.9)$ & $37(77.1)$ & & $1.17(0.16-8.41)$ \\
\hline
\end{tabular}




\section{Discussion}

This study was undertaken to determine the short term outcome and the factors influencing such outcome of asphyxiated babies admitted into our NSCBU. Though adherence to the biochemical parameters for defining asphyxia was not possible because of limited laboratory support in our centers, the use of Apgar score at 1 minute to define asphyxia is acceptable in third world countries as it offers a standardized, effective, and convenient assessment for newborn infants. ${ }^{1,16-18}$

Most $(63.3 \%)$ of these asphyxiated babies were delivered outside the hospital facility as would be expected, this being the only emergency newborn unit providing tertiary neonatal care in Enugu municipality. However, this differs from most other studies. ${ }^{2,4}$ That as much as $36.7 \%$ of these births took place within the hospital facility leaves a lot to be desired. It highlights the delay in intervention by the obstetricians, knowing the dangers posed by asphyxia, knowing that the quality of medical care at birth is crucial for the overall newborn mortality and long-term outcomes.

There is almost equal male and female proportion in this study. This is also unlike most other studies. ${ }^{2,411}$ Could this be due to the maternal and child health campaigns in Enugu in recent years? However, the distribution of the sexes in this study is similar to that in a study in Zamfara. ${ }^{19}$ The overall mortality was high $(38.7 \%)$ with the in-hospital mortality being relatively low (14.5\%) and comparable with other studies. ${ }^{2,4,6,20}$ The high overall mortality was due to the burden of out-born deaths with $8(16 \%)$ of them dying in the first 24 hours. The difference between in-born and out-born survival was statistically significant, as would have been expected. This high mortality among the out-born must have emanated from the poor neonatal resuscitation skills, the lack of resuscitative equipment, lack of manpower in neonatal resuscitation at birth and the delay in transporting the asphyxiated newborn to a higher center considering that Padayachee, et al in Johannesburg, noted that bag-mask ventilation at birth significantly affected outcome. ${ }^{2}$ This is further buttressed by the fact that the in-born who were instantly attended to with bag-mask ventilation with or without oxygen and chest compression as the case may be were about 1.2 times more likely to survive asphyxia when compared with the out-born. However, this finding is at variance with that of Ilah, et $\mathrm{al}^{19}$ in Zamfara who reported that mortality was not associated with place of birth.

Again, the mean duration of hospitalization of the asphyxiated babies in this study was a little more than a week and while the survivors spent almost two weeks on admission, the non-survivors spent one week. This denotes the interval taken for the newborn to recover from the multiple effects of asphyxia. This finding is similar to that of Lee in Southern Nepal. ${ }^{21}$ However; it differs from the findings of Padayachee in Johanesburg. ${ }^{2}$

Interestingly, this study found that the more the BW, the higher the chances of survival of asphyxia. This must have been as a result of the role played by birth weight in ensuring prevention of hypothermia, stability of blood glucose and immunity. These having been found to be poor prognostic factors in asphyxia. ${ }^{6}$ Previous studies in Brasil and Southern Nepal have also noted high mortality among asphyxiated LBWs. ${ }^{21,22}$ This is also given more credence by the fact that on multivariate analysis, the LBWs were 2 times and about 5 time less likely to survive birth asphyxia compared with the normal BWs and macrosomias respectively.

With regards to GA, it was observed that most of the pre-terms in this study died while the term and post-date babies survived asphyxia better than the pre-terms. This may be reflecting the ability of the term and postdate babies in handling hypoxemia, metabolic acidosis, and other problems associated with asphyxia better. Also, this high mortality probably must have arisen from the logistics and delay in bringing these babies to a higher center. In fact the asphyxiated pre-term babies were about 11 times less likely and about 9 times less likely to survive asphyxia compared with the terms and post-dates respectively. This means that with regards to birth asphyxia, gestational age is both a risk factor for and a predictor of outcome., ${ }^{3,21}$ Relatively, the post-dates seemed not to be at any greater risk for birth asphyxia compared with the term babies. These observations also agree with the findings of Lee, et al in Nepal. ${ }^{21}$

Birth asphyxia deaths occurred more among the severely asphyxiated babies compared with those who suffered moderate asphyxia. This may also be related to the free radicals and other chemicals released in severe asphyxia with apoptotic effects. Other studies have also noted that severe $\mathrm{BA}$ is the most frequent cause of perinatal and neonatal death as well as of severe injury to central 
nervous system. ${ }^{3}$ Hence, it could be said that the more the degree of asphyxia, the less likely are the chances of survival. This is further highlighted in this study by the fact that those babies who suffered moderate asphyxia were about three times more likely to survive compared with those who suffered severe asphyxia. This finding is also in agreement with other studies. ${ }^{6,19}$ However, while Apgar score cannot predict individual mortality, it should be noted that the degree of asphyxia using Apgar score at one minute predicts mortality. Previous studies have also made this valid observation. ${ }^{6}$

Parental education was also significantly associated with increased chances of birth asphyxia survival. The parental education may have increased asphyxia survival by influencing maternal nutritional status and food choices, which will ultimately reduce the risk of LBW, healthcare-seeking and access to health care services during the antenatal and intrapartum periods, as well as reduce the delay in going to higher centers in the event of adverse outcomes during delivery. This finding also agrees with that of Lee, et al. ${ }^{21}$

\section{Conclusion}

Birth weight, gestational age, degree of asphyxia, place of delivery and parental education all predicts survival in birth asphyxia.

The study confirms birth asphyxia as a significant cause of mortality in NBSCU of ESUT Teaching Hospital.

\section{Recommendations}

Further studies are required in determining the role of these predictors of survival among asphyxiated babies. The high in-born survival should be the benchmark for care and survival in NBSCU especially among the outborn. Also, greater attention needs to be paid to the preterm and LBWs in NBSCU as they constituted the bulk of the mortality.

The findings in this study also underscore the need to increase the girl child enrollment into Nigerian Secondary schools.

\section{Limitations}

Lack of adjusting for co-morbid causes of mortality. Inability to do Arterial Blood Gas estimations to correlate acidosis.

\section{Author contribution}

NDU conceived the study, designed questionnaire, collected data and directed analysis. ECA contributed in questionnaire design, collected data and carried out data analysis. UE contributed in questionnaire design and data collection. All authors participated in manuscript writing.

The authors hereby disclose that there was no financial support from any group, Institution or company.

\section{Funding}

None.

\section{Conflict of interest}

The authors declare no conflict of interest.

\section{References}

1. Kinoti SS. Asphyxia of the newborn in East, Central and Southern Africa. East Afri Med J. 1993;70:422-433. PubMed.

2. Padayachee N, Ballot DE. Outcomes of neonates with perinatal asphyxia at a tertiary academic hospital in Johannesburg, South Africa. S Afr J CH. 2013; 7(3):89-94. PubMed. DOI:10.7196/SAJCH.574.

3. Golubnitschaja O, Yeghiazaryan K, Cebioglu M, Morelli M, Herrera-Marschitz M. Birth asphyxia as the major complication in newborns: moving towards improved individual outcomes by prediction, targeted prevention and tailored medical care. EPMA J. 2011;2(2):197-210. PubMed.

4. Shireen N, Nahar N, Mollah AH. Risk factors and short term outcome of birth asphyxiated babies in Dhaka Medical College Hospital. Bangladesh J Child Health. 2009;33(3):83-89.

5. Halloran DR, McClure E, Chakraborty H, Chomba E, Wright LL, Carlo WA. Birth Asphyxia survivors in developing country. J Perinatol. 2009;29(3):243-249. PubMed.

6. Ondoa-Onama C, Tumwine JK. Immediate outcome of babies with Low Apgar Score in Mulago Hospital, Uganda. East Afr Med J. 2003;80:22-29.

7. Lawn JE, Cousens S, Zupan J. Lancet Neonatal Survival Steering Team: 4 million neonatal deaths: When? Where? Why? Lancet.2005; 365: 891-900. PubMed.

8. Bryce J, Boschi-Pinto C, Shibuya K, Black RE. WHO. Child Epidemiology Reference Group. WHO estimates 
of the causes of death in children. Lancet. 2005;365:11471152. PubMed.

9. WHO. Basic newborn resuscitation: a practical guide. WHO Report 1997;2-3.

10. UNICEF. State of the World Children (SOWC) 2016. 11. Siva Saranappa SB, chaithanya CN, Madhu GN, Srinivasa S, Manjunath MN. Clinical profile and outcome of perinatal asphyxia in a tertiary care centre. Curr Pediatr Res. 2015; 19(1\& amp; 2):9-12. PubMed.

12. WHO. Birth Asphyxia - Summary of the previous meeting and protocol overview 2007. http://www.curoservice.com/health_professionals/news/pdf/10-092007_birth_asphyxia02.pdf (assessed August 3, 2016) 13. American Academy of Pediatrics Committee on Fetus and Newborn, American College of Obstetricians and Gynecologists Committee on Obstetric Practice. The APGAR Score. Pediatrics. 2015; DOI: 10.1542/ peds.2015-2651

14. Schmidt B, Kirpalani H, Rosenbaum P, Cadman D. Strengths and limitations of the Apgar score: a critical appraisal. J Clin Epdemiol. 1988;41(9):843-850. PubMed. 15. Nelson KB, Ellenberg JH. Apgar scores as Predictors of Chronic Neurologic Disability. Pediatrics. 1981;68(1):3644. PubMed.

16. Ahmadpour-Kacho M, Asnafi N, Jaradian M, Hajiahmadi M, Taleghani N. Correlation between Umbilical Cord $\mathrm{pH}$ and Apgar Score in High-Risk Pregnancy. Iran J Pediatr. 2010;20:401-06. PubMed.
17. Thomson AJ, Searle M, Russell G. Quality of Survival after Birth Asphyxia. Arch Dis Child. 1997;52:620-26. PubMed.

18. Ellis M, Manandhar N, MAnandhar DS, deLCostello AM. An Apgar Score of Three or Less at One Minute is not diagnostic of Birth Asphyxia But is a Useful Screening Test for Neonatal Encephalopathy. Indian Pediatr. 1998;35:415-21. PubMed.

19. Ilah BG, Aminu MS, Musa A, Adelakun MB, Adeniji AO, Kolawole T. Prevalence and Risk Factors for Perinatal Asphyxia as Seen at a Specialist Hospital in Gusau, Nigeria. Sub-Saharan Afri J Med. 2015;2(2):64-69. PubMed.

20. Ekwochi U, Ndu IK, Nwokoye IC, Ezenwosu OU, Amadi OF, Osuorah DIC. Pattern of morbidity and mortality of newborns admitted into the sick and special care baby unit of Enugu State University Teaching Hospital, Enugu state. Niger J Clin Pract. 2014;17:346-51. PubMed. 21. Lee ACC, Mullany LC, Tielsch JM, Katz J, Khatry SK, LeClerg SC. Risk Factors for Neonatal Mortality due to Birth Asphyxia in Southern Nepal: A Prospective, Community-based Cohort Study. Pediatr. 2008;121(5): e1381-e1390. doi: 10.1542/peds.2007-1966.

22. de Almeida MFB, Moreira LMO, Vas dos Santos RM, Kawakima MD, Anchieta LM, Guinsburg R. Early neonatal deaths with perinatal asphyxia in very low birth weight Brazilian infants. J Perinatol. 2015;35:954-957. doi:10.1038/jp.2015.114. 